\title{
DIGICULTURE - THE DEVELOPMENT OF OPEN EDUCATION LEARNING FOR DIGITAL SKILLS TRAINING
}

\author{
Diana Andone, Andrei Ternauciuc, Radu Vasiu, Vlad Mihaescu, Silviu Vert, \\ Politehnica University of Timisoara, Romania
}

\section{Abstract}

UniCampus, online learning environment started in 2014, as an attempt to provide the first Romanian language MOOC-like Massive Open Online Courses. For the development of the DigiCulture project we decided to extend the existing UniCampus platform with a new DigiCulture theme. This paper presents the technical development, based on the Moodle framework, with new user interactions. The DigiCulture project develops free, online short courses dedicated to adults with low digital skills. The shortage of digital skills in Europe reported in 2016 in "European Digital Progress Report EDPR" of the European Commission: $45 \%$ of Europeans have insufficient or no digital skills. As there are big differences between the countries that are partners in DigiCulture, we propose an integrated approach for course development, but with national personalization as language, study cases. These implementation and personalization are presented in this paper.

\section{Introduction}

The shortage of digital skills in Europe reported in 2016 in "European Digital Progress Report EDPR" (ECDL, 2016) of the European Commission: 45\% of Europeans have insufficient or no digital skills. Based on the Digital Economy and Society Index (DESI) (European Commission, 2016b) index of 2017 there are big differences between the countries that are partners in this project. Denmark has one of the most advanced digital economies in the EU, while Lithuania and Austria are in the middle, but Romania and Italy have the lowest scores on the DESI. Studies performed by authors in the cultural and creative industries (Ginsburg, Sabatini, \& Wagner, 2000), in the last 3 years in different countries showed a large majority scoring lower or basic level for the 21 digital competences (Vorikari et al., 2016). The usage of web, mobile, social and analytical tools is permeating the length and breadth of the culture, creative industries, areas which until recently have been reluctant to embrace the use of the new technologies. Eurostat 2017 (European Commission, 2016a) identifies young adults from the creative industries as the 
most at risk for unemployment from the 22-36 years old, and lack of entrepreneurial and digital skills.

We aim to create a sustainable and efficient open education program - DigiCulture dedicated to adult learners with low digital skills and low-qualified adults involved in the creative industries sector. This paper analyses the need for such an educational program and presents the instructional modelling for an open, online and blended learning, training program based on a Massive Open Online Course model and the UniCampus virtual environment (Andone, Vasiu, \& Ternauciuc, 2017). The modelling takes into consideration the existing UniCampus, which is further developed in order to integrate the requirements of low digital skills adults, Open Education, e-assessment and a mobile environment. The DigiCulture educational program is fully integrated in the UniCampus as an online component, a blended learning model and easy-to-access features in the mobile app.

\section{Methodology}

The main research question of this paper is: how can we best adapt an existing Learning Management System (LMS), namely Moodle, to the specific requirements of non-technical learners, with the purpose of increasing the platform's effectiveness and level of adoption.

In order to answer this question, a qualitative approach was considered best suited. An exploratory analysis of the features considered essential for the adoption of the platform by low-skilled learners was based on the authors' multi-year experience in designing the necessary tools and the courses themselves, as well as in tutoring said courses.

The vast array of tools made available the open-source LMS Moodle was trimmed to the necessary minimum, and a large emphasis was placed on the functional usability of the platform from the point of view of the target audience. Starting with the building of a custom graphical interface, and continuing with testing and validating a suite of thirdparty extensions which provide - in part - the stated objective, we designed a simplified version of Moodle, aimed at non-technical learners, with limited digital skills as a whole, and e-Learning experience in particular.

\section{Results}

The UniCampus platform started as an attempt to provide the first Romanian language MOOC-like courses. Development began in 2014, and by 2016 three courses were completed and piloted, with an additional two in advanced planning stages (Andone, Vasiu, \& Ternauciuc, 2017). 
The platform was based on Moodle, the popular open-source learning management system, which was completed with third-party extensions aimed at complementing and facilitating the learning process, all the while providing course participants with social media connections in line with the constructivist philosophy that Moodle promotes (Jordan, 2013).

Since its launch, UniCampus was constantly adapted to the needs of the users (course participants, course tutors, managers, etc.) and many extensions were functionally tested and uninstalled if found to be insufficiently useful. Moodle itself was affected by multiple updates, which were tested and validated inside the development environment, then applied to the production environment. Currently (January 2020), the UniCampus platform uses the latest Moodle 3.8 stable version, as well as the latest versions of the handful of extensions that were deemed useful for the aim of the platform.

Some of the plugins were not adapted by their developers once the newer Moodle versions were released, which led to broken functionalities. If those features were considered crucial to the platform, they were sometimes replicated by the developer team behind UniCampus.

One such extension is the graphical interface itself, which for the latest Moodle version required a complete rewrite. The current UniCampus theme was therefore entirely developed in-house, with the obvious advantages of complete control over the user interface and experience, as well as the possibility of functional optimizations, which are crucial for any MOOC-like platform catering to multiple concurrent users (Figure 1).

The starting point of the current interface was represented by the Classic theme, which was extended with the appropriate colours and graphical elements of the platform's visual identity.

Aside from simplicity, another directive of the graphical design philosophy was based on redundancy: controls we considered essential were duplicated in a top menu, via graphical icons leading users to a handful of critical aspects, such as the events calendar, the file repository, or the control preferences interface. The regular way of accessing these settings is also present, allowing users familiar with Moodle to continue to use the platform efficiently. 


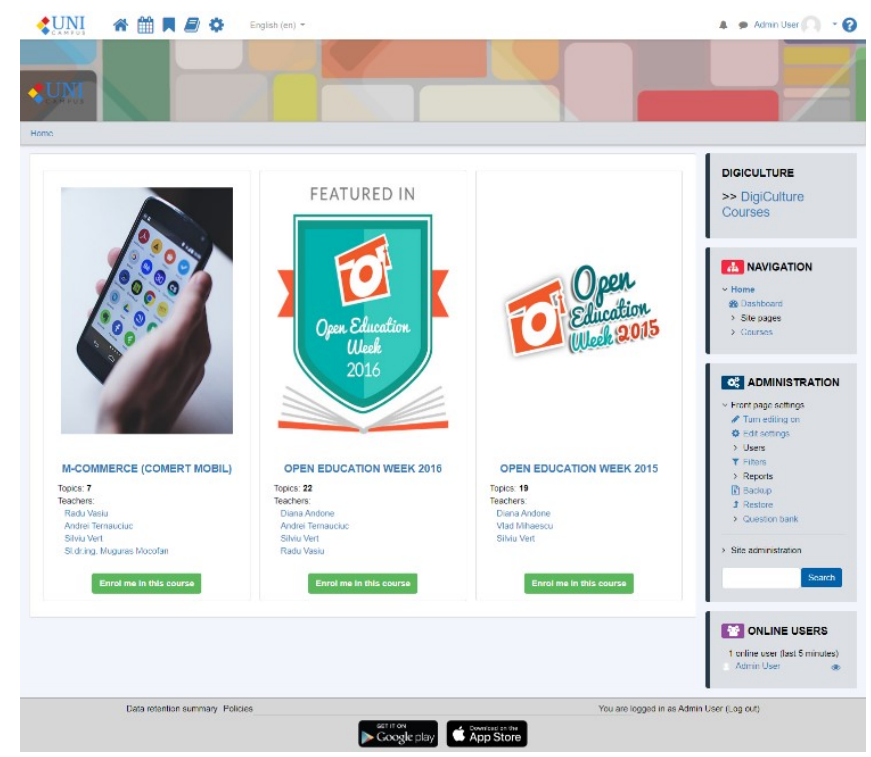

Figure 1. The UniCampus platform main interface

Most of the graphical elements were replicated in the new version of the theme, including the presentation cards for the featured courses on the frontpage of the platform. These cards were designed to provide at a glance all the relevant information for each featured course, including the cover image, the title, number of topics, list of tutors, as well as the direct link to the course for easy enrolment.

The same information is provided on the presentation website for the UniCampus courses, which is actually a completely different application than the Moodle-based UniCampus platform (Figure 2). The purpose of this interface was to provide an external perspective on the main platform's content, which suffers from most of the content management systems' shortcomings: adherence to strict mechanisms due to the Moodle framework, unnecessary complex handling of access controls, vulnerability to potential errors in the LMS's source code, etc. A simple presentation website, which reads the information directly from the database, provides unauthenticated visitors with all the necessary information needed before committing to the creation of an account with which to enrol in existing courses.

All of these considerations were based on the UniCampus stated objective of hosting MOOCs in the Romanian language. And since the intended users of such a platform include those with limited digital skills, the design of the application was directed from the start towards a user-friendly, optimized and efficient user-interface, available on a wide variety of devices. 

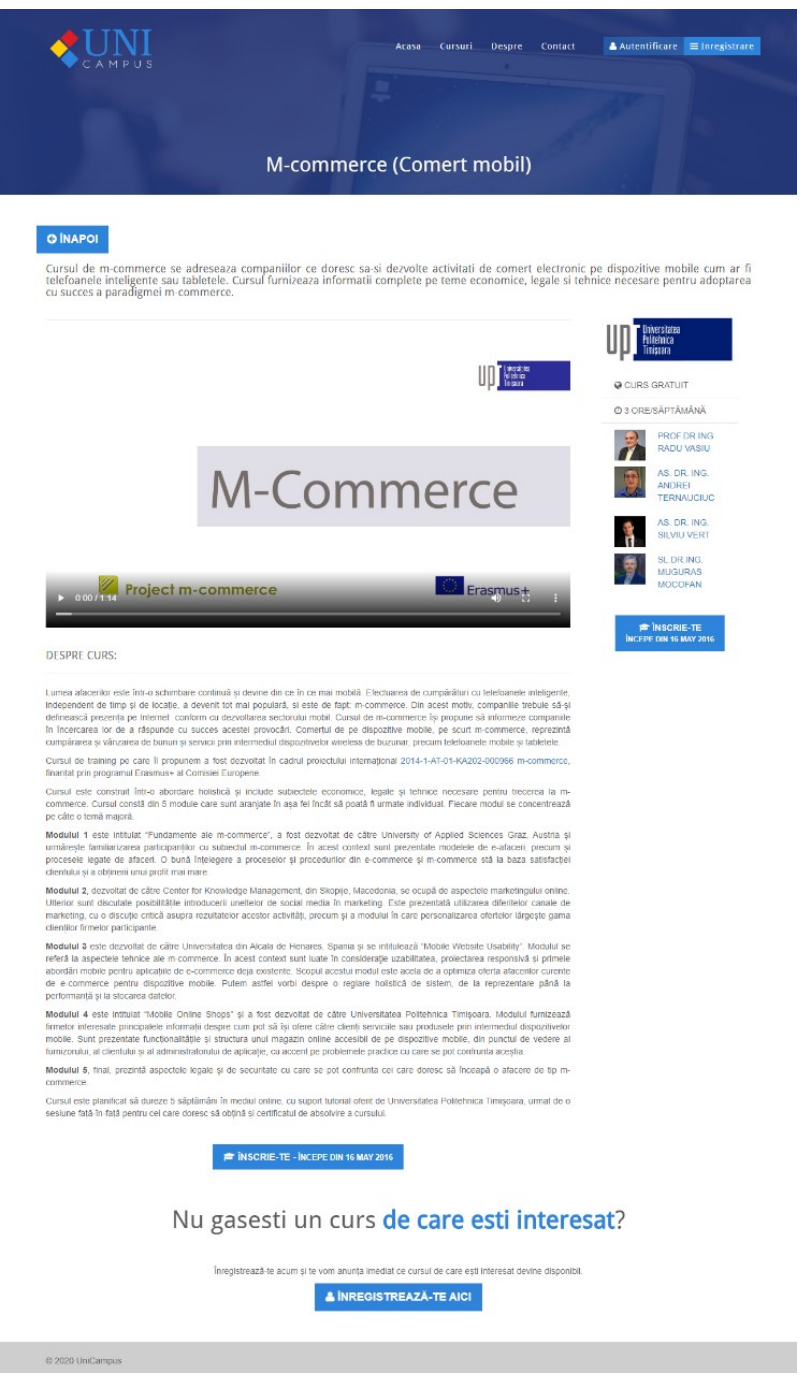

Figure 2. UniCampus presentation website

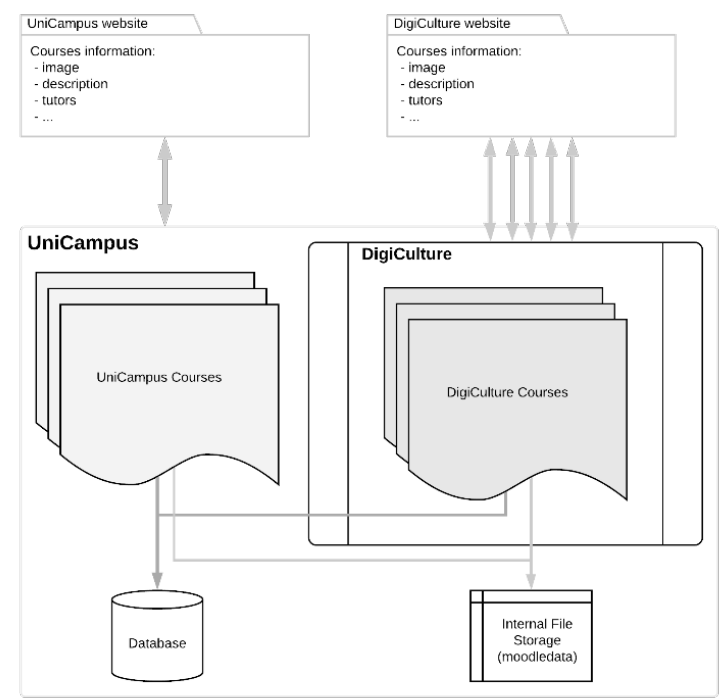

Figure 3. Integration of the DigiCulture application inside the UniCampus platform

This is the reason why for the development of the DigiCulture application aimed at hosting instructional courses, we decided to extend the existing UniCampus platform by creating 
a separate section inside the course structure, in order to benefit from all of the facilities that the platform already provided (Figure 2). With a few improvements, we were able to seamlessly integrate the two applications which look and feel differently, but share the same underlying Moodle code. This greatly reduces the cost of maintaining multiple instances of almost identical platforms.

The most obvious difference is the graphical interface. The DigiCulture platform needed to follow the visual identity guides provided by the project, but still adhere to the restrictions of a Moodle theme.

The DigiCulture theme was therefore designed using the Moodle framework as the basis on which all the graphical elements and user interactions were built. And using Moodle's feature of allowing category themes (the possibility to use a different interface on all of the courses which are part of a certain category of courses, instead of the default template), we were able to switch the current theme by simply accessing the list of courses (or any individual such course) in the DigiCulture section of the platform. Also, in order to improve the appeal of the interface, the list of courses was replaced by a "card deck" of courses for each sub-category, similarly to the UniCampus featured courses display (Figure 3).

Another difference between the two platforms was the need for more interface languages. While UniCampus was aimed at Romanian users (and therefore provided only Romanian and English language packs), the DigiCulture project has partners from 6 different countries, which prompted the need for four additional language packs; these, luckily, were provided officially by Moodle via the administration interface.

One of the biggest changes that needed to be done was one in perspective. While UniCampus caters to users somewhat fluent in IT, the target group for DigiCulture consists of users with limited IT skills, mainly artists who are just beginning to grasp the fundamental concepts of the Digital World. 
Andone, D., Ternauciuc, A., Vasiu, R., Mihaescu, V., \& Vert, S.

Digiculture - The Development of Open Education Learning for Digital Skills Training

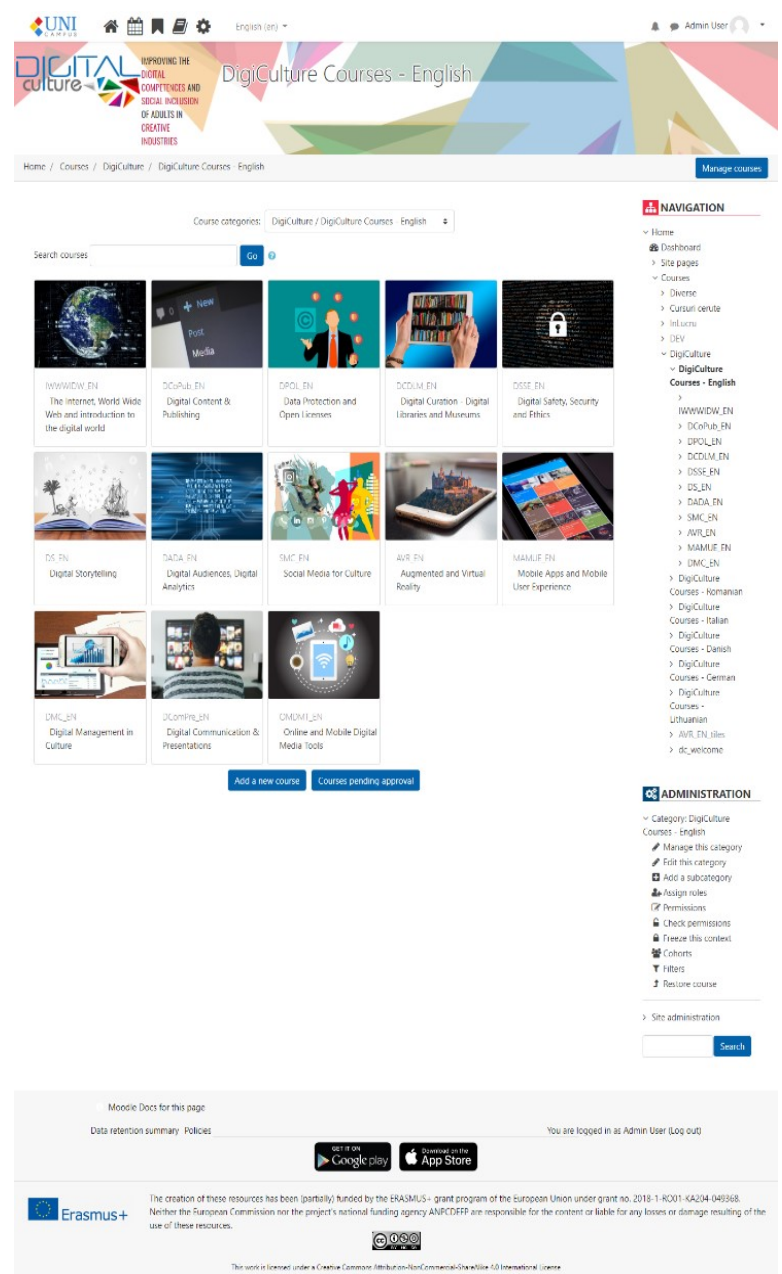

Figure 4. List of courses inside the DigiCulture category 


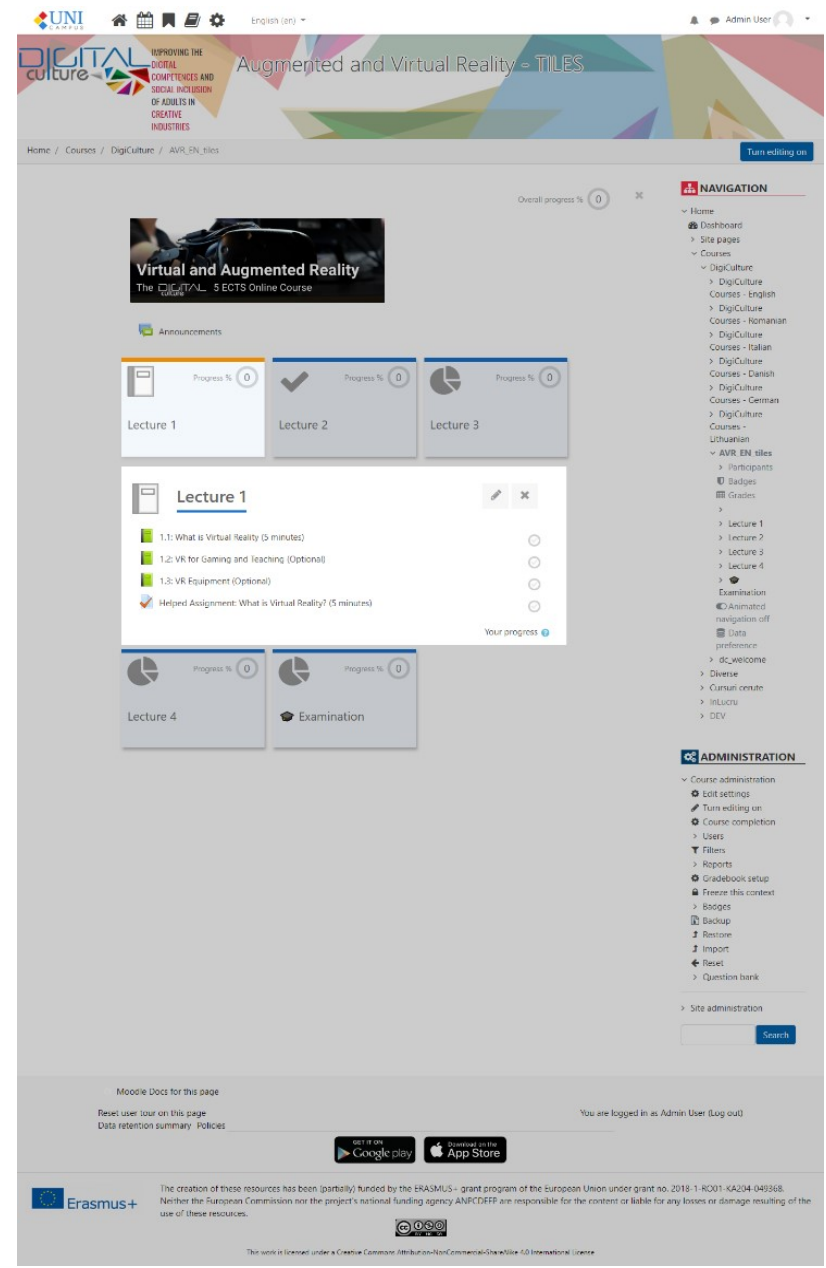

Figure 5. Course using the Tiles format

As such, we tested and ultimately chose an improved version of the standard course format (the way course activities and resources are organized), called the Tiles Format. This extension allows to efficiently access only parts of a course at a time, while providing relevant information like the number of resources/activities, the degree of completion, all in a visually pleasing package (Figure 4 ).

Of special interest is the ability to quickly visualize the current status of the course completion, since this course format can display the global course completion ratio, as well as a per-topic percentage of activities completed, according to the course completion criteria which were set-up by the course creators. This provides all learners with at-aglance status report of their learning achievements.

In order to better promote the courses that were developed as part of the DigiCulture project, an API was developed aimed at easily bringing essential information pertaining to the courses to the project website (Figure 5). The information which is sent includes:

- The course title;

- $\quad$ The course cover image; 
- A direct link to access the course on the DigiCulture platform.

This information is the one provided in the course description on the Moodle-based DigiCulture platform, and any change reflects automatically on the presentation website. This greatly reduces to complexity of the operations needed to update course information (such as the course image, the title, the description, etc.) since one only needs to modify it inside the platform.

Another objective of this mechanism is to provide any interested parties with easy access to the enrolment process. Many other improvements were also made, with the main purpose of providing a cleaner, more friendly and intuitive interface through which anyone, regardless of their level of competence in ICT, could access the content and experiences provided by the developed courses.

\section{Interpretation and Conclusions}

The DigiCulture Virtual Learning $\mathrm{Hub}$ is an innovative multilingual ICT-based environment to promote collaborative learning using connectivist social networking as an instructional method, OERs as the main content, and open digital credentials as recognition and validation of digital skills which can be applied to all ages, genders, cultural backgrounds and levels of digital education in order to promote social inclusion at a digital level. The next step of our project implies usability evaluations of the environment as to seek if the proposed the user-friendly interface and the mobile interface will encourage all users to access it, engage in a variety of open learning activities, connect with other cultural actors and develop their own digital skills.

\section{References}

Andone, D., Vasiu, R., \& Ternauciuc, A. (2017, April). UniCampus: the First Courses in a Romanian MOOC. Paper presented at the IEEE Global Engineering Education Conference (EDUCON), Athens, Greece, 2017.

Council of the European Union. (2016, May 30). Council conclusions on developing media literacy and critical thinking through education and training. Retrieved from https://www.consilium.europa.eu/en/press/press-releases/2016/05/30/eycsconclusions-developing-media-literacy/

ECDL. (2016). Perception and Reality: Measuring Digital Skills in Europe. Retrieved from http://www.ecdl.org.ro/m/en/news-article/new-ecdl-foundation-position-paperperception-reality-measuring-digitalskills-in-europe_611.html

European Commission. (2016a). European Skills Agenda. Retrieved from http://ec.europa.eu/social/main.jsp?catId=1223 
European Commission (2016b). The Digital Economy and Society Index (DESI). Retrieved from https://ec.europa.eu/digital-single-market/en/desi

Ginsburg, L., Sabatini, J., \& Wagner, D. A. (2000). Basic Skills in Adult Education and the Digital Divide. Published in Learning to Bridge the Digital Divide. Retrieved from https://www.oecd.org/site/schoolingfortomorrowknowledgebase/themes/ict/basicskil lsinadulteducationand thedigitaldivide.htm

Jordan, C. (2013). Comparison of International Baccalaureate (IB) chemistry students' preferred vs actual experience with a constructivist style of learning in a Moodle e-learning environment. International Journal for Lesson and Learning Studies, 28(2), 155-167.

Vorikari, R., Punie, Y., Carretero Gomez, S., \& van den Brande, G. (2016). DigComp2.0: The Digital Competence Framework for Citizens report by the by the JRC Science. Retreived from https://ec.europa.eu/jrc/en/publication/eur-scientific-and-technicalresearch-reports/digcomp-20-digital-competence-framework-citizens-update-phase-1conceptual-reference-model 